\title{
Irrigation sedimentation tanks in the bed of the pumping station inlet channels
}

\author{
Dilshod Bazarov ${ }^{1}$, Nikolai Vatin ${ }^{2}$, Farrukh Kattakulov ${ }^{1}$ Oybek Vokhidov ${ }^{*}$, Iroda \\ Rayimova, and Ikboloy Raimova ${ }^{1}$ \\ ${ }^{1}$ Tashkent Institute of Irrigation and Agricultural Mechanization Engineers, Tashkent, Uzbekistan \\ ${ }^{2}$ Peter the Great St. Petersburg Polytechnic University, Saint Petersburg, Russia
}

\begin{abstract}
The article analyzes the dynamics of channel processes in the irrigation pumping station inlet channels. The field studies of hydraulic and alluvial sediment regimes in the supply channels of pumping stations are analyzed and summarized. The studies of supply channel water flow under conditions of extremely high turbidity of the flow and variability of the morphometric characteristics of the channel are presented. The conditions under which the Saint-Venant equations satisfactorily describe the channel flows in the bed of the supply channels are given. Saint-Venant's twodimensional equations were numerically implemented using an explicit finite-difference scheme. In addition, the results of calculations of the flow field in the supply channels are presented. According to the results of numerical studies, the width of the sedimentation tank was taken to be equal to the design width of the channel, and the speed of water flow in it was $0.25 \mathrm{~m} / \mathrm{s}$. The length of the sedimentation tank, ensuring the retention of sediments of the finest fraction $(0.05 \mathrm{~mm}$ in diameter $)$, was $1042 \mathrm{~m}$. The siltation time of the sedimentation tank can be reduced by $15 \ldots 20 \%$ and amount to about 15 months, considering the unevenness of the velocity distribution diagram in the horizontal plane and the trapezoidal crosssection of the clarifier. Nevertheless, the arrangement of two parallel chambers of the sedimentation tanks makes it possible to be stable for a sufficiently long time.
\end{abstract}

\section{Introduction}

Forecasting the influence of the operating mode of pumping stations on the dynamics and hydrodynamic characteristics of the flow is one of the most important tasks of channel hydraulics. Especially if the water intake is carried out in a damless way, one of the muddiest rivers in Central Asia, the Amu Darya. The object of the study is the inlet channel of the pumping stations of the pumping station cascade of the Karshi Main Channel $(\mathrm{KMC})$, where the above operational problems are present [1-4]. A sharp change in the

\footnotetext{
*Corresponding author: vohidov.oybek@bk.ru
} 
hydraulic and alluvial regime of the river, from where the damless water intake is carried out, significantly affects the regimes of the supply channel. There has been an intensive increase in the incoming sediments in recent years, both introduced and drawn. For the inflow of a large amount of bottom and large fractions of suspended sediments at the head part of the water intake, the entire section of the supply channel to the first pumping station is brought in by sediments. Some sediments are transported by water to the concrete section of the KMC. Increasing the operating efficiency of all pumping stations of the cascade and reducing abrasive wear of pumping units, ensuring a guaranteed volume of clarified water to the pumping station, requires clarifying the flow at the inlet section of the machine channel. Particular attention is paid to reducing the flow of sediments into the front chambers of pumping stations to ensure the required volume of water intake [4-6]. The sediment inflow into the front chambers of pumping stations affects the reliability and operation of the pumping station and reducing its throughput. To ensure a guaranteed volume of water with a minimum volume of bottom and suspended sediments is considered an urgent task. The dynamics of the hydraulic and alluvial flow regimes in the bed of the pumping station inlet channels were studied in [7-15]. Sediments occur due to the hydrodynamic effect of the flow on the stand plate in the presence of cavitation, eroding water flow rate in the channels, and dynamic instability of large soil channels with wind waves [16-18]. In addition, the water flowof the Amu Darya River has a high degree of sediment saturation. As already mentioned above, there has recently been a sharp change in the hydrological regime of the river. There are intense deformations of the supply channel border since it runs on easily washed-out soils [19-29].

This research was aimed at improving the operating conditions in the supply channels of pumping stations.

The following tasks are formulated to achieve this aim:

- developing of the two-dimensional mathematical model of the flow in pumping station inlet channels;

-hydraulic study of a sedimentation tank in the bed of the irrigation pumping station inlet channel. 


\section{Methods}

The analytical research method was applied to assess the previously obtained field observation data of the Karshi Main Channel and to create a mathematical model.

\section{Results and discussion}

In irrigation practice, sedimentation tanks are located at the head of the channels, and insystem sedimentation tanks are used to retain sediment. The first ones are arranged at the head of the system on the inlet section of the main channel and provide for the deposition of a part of the largest fractions of sediments that cannot be transported down by the main channels. In the in-system sedimentation tanks, arranged in various sections of the channels located below, the flow is clarified a second time. The remaining sediment can be transported by water flows of irrigation channels to irrigated fields. In this type of sedimentation tank, there are more possibilities to maintain the desired filling depths, heads, and velocities using the regulators located above and at the end of the sedimentation tank.

Studies of the transporting capacity of the Amu Darya irrigation systems, located in the middle course of the river [4], showed that the head sedimentation tanks on large irrigation systems could not ensure that the on-farm network was not covered with channels of the same order. Here, the device of in-system sedimentation tanks is needed. About $70 \%$ of sediments should be retained in the sedimentation tanks [4]. During the entire irrigation period in the on-farm network, it could transport up to $30 \%$ of the total runoff of suspended sediment entering the system, of which $20 \%$ will be released to the fields, and $10 \%$ will be deposited in the on-farm network.

Sedimentation tanks on irrigation systems in the lower reaches of the Amu Darya river [4] mainly represent the widened and deepened head sections of the channels. The sediments are continuously removed by the hydromechanical method. The length of the head sedimentation tanks is $1000 \ldots .2500 \mathrm{~m}$, and the length of the intrasystem tanks is $400 \ldots 1500 \mathrm{~m}$.

Until now, there are no practical algorithms for solving three-dimensional problems in a complete formulation. Nevertheless, it was shown in [6] that when introducing the scale of consideration:

$$
M_{L}=L_{n}^{2} T
$$

where $L_{n}$ is the linear scale in plan (moreover, $L_{n}>>h$, where $h$ - flow depth); $T=L_{n} / U$, where $U$ is the characteristic flow rate and provided that

$$
\frac{\rho_{\max }-\rho_{\min }}{\rho_{\text {max }}+\rho_{\text {min }}}<<1
$$

general equations of hydrodynamics [7] are as follows: 


$$
\begin{aligned}
& \frac{\partial u_{i} \rho}{\partial t}+\frac{\partial u_{i} u_{j} \rho}{\partial x_{j}}+\frac{\partial \rho}{\partial x_{i}}=\frac{\partial \tau_{i j}}{\partial x_{j}}+g_{i} \rho \\
& \frac{\partial \rho}{\partial t}+\frac{\partial u_{i} \rho}{\partial x_{i}}=0 ; \quad \frac{\partial S_{r}}{\partial t}+\frac{\partial S_{r} u_{j}}{\partial x_{j}}=q_{S r} \\
& \rho=f\left(S_{r}\right) ; \quad i=1,2,3,
\end{aligned}
$$

where $u_{i}$ is the projection of the current velocity vector onto the axis $x_{i}, p$ is the hydrodynamic pressure, $\tau_{i}$ is the shear stress tensor component, $\rho$ is the density, $g_{i}$ is the component of the gravity acceleration vector, $q_{S r}$ is the internal sources of substance for Newtonian fluid, $v$ is the kinematic fluid viscosity, $S_{r}$ is the some substance that determines the density (temperature, salinity) and can be reduced to the following system of equations:

$$
\begin{gathered}
\tau_{i j}=\left(\frac{\partial u_{i}}{\partial x_{j}}+\frac{\partial u_{j}}{\partial x_{i}}\right) v \rho \\
\left\{\begin{array}{l}
\frac{\partial u_{i}}{\partial t}+\frac{\partial u_{i} u_{j}}{\partial x_{j}}+\frac{\partial u_{i} w}{\partial z}+g\left(\frac{\partial z_{\Gamma}}{\partial x_{i}}+\frac{1}{\rho} \int_{z}^{z_{\Gamma}} \frac{\partial \rho}{\partial x_{i}} \partial z\right)=\frac{\partial}{\partial z} v_{T} \frac{\partial u_{i}}{\partial z}+\frac{\partial}{\partial z} \mu \frac{\partial u_{i}}{\partial z} \frac{1}{\rho} \\
\frac{\partial u_{i}}{\partial x_{i}}+\frac{\partial w}{\partial z}=0 \\
\frac{\partial S_{r}}{\partial t}+\frac{\partial S_{r} u_{j}}{\partial x_{j}}+\frac{\partial S_{r} w}{\partial z}=\frac{\partial}{\partial z} D \frac{\partial S_{r}}{\partial z}+q_{S z} \\
\rho=\rho\left(S_{r}\right)
\end{array}\right.
\end{gathered}
$$

where $S_{r}$ is the average concentration of a substance on a scale (1), $D$ is the vertical diffusion coefficient, which is the analog of turbulent viscosity coefficient $v_{T}$. It is usually assumed that $D=\alpha v_{T}$.

The same equations can be obtained from the Reynolds equations with the additional assumption of neglecting turbulent interactions between water jets in the plan. Also, two different approaches lead to the same equations. However, in terms of expected results, these approaches are not equivalent. All dependent variables $u_{i}, q_{i}$, and $h$ in (4) have different values. The values depend on whether these equations are obtained from the Reynolds equations or directly from the conservation laws. In the first case, these values are initially averaged on probability and then on a large scale. In the second case, these are actual values averaged over the same scale.

The equation system (4) is obtained from the laws of conservation of momentum and mass without any specific assumption about the rheology of the fluid. To close the system of equations, it is sufficient to specify the relationship between the shear stresses at the bottom ( $\tau i)$ and the rest of the flow characteristics. It is usually believed that the ratio can express this relationship

$$
\tau_{i}=\lambda U_{i}|U| / 2
$$

where $\lambda$ is the scalar coefficient of hydraulic friction, which is calculated by Manning's formula: 


$$
\lambda=\frac{2 g}{C^{2}}=\frac{2 g n^{2}}{h^{1 / 3}},
$$

where $C$ is the Chezy coefficient, $n$ is the roughness coefficient.

All of the above is also true for a boundary-free flow. If the flow is considered near a rough vertical wall, then, since $\tau_{c}$ and $\tau_{b}$ are determined, respectively, by the roughness of the walls and bottom, and the assumption about the smallness of the change in all characteristics along the horizontal coordinate compared to the change along the vertical coordinate leads to the fact that in the first approximation, in the expansion at the small parameter $\alpha=L / h$, leads to hydrostatic pressure on a given scale, i.e.:

$$
\frac{\partial P}{\partial z}=g \bar{\rho}
$$

Passing to the roughness coefficients (7) can be written in the form:

$$
\frac{L_{n}}{h}>\left(\frac{n_{c}}{n_{b}}\right)^{2}
$$

The expression (7) is one of the main restrictions imposed on the range of applicability of the Saint-Venant equations.

The conditions for applying equations (5), including the setting of boundary conditions, are well described in [8-11].

In this paper, the two-dimensional Saint-Venant equations were numerically implemented using the explicit finite-difference scheme of A.N. Militeyeva [8]. Hydraulic numerical experiments to study the flow regime in a river bed were carried out by the establishment method, i.e., a certain initial water level in the calculated fragment, the water flow rate at the inlet to this fragment, the water flow is taken into the channel, and the curve of the relationship between the flow rate and the water level at the outlet from the calculated fragment were set. After that, calculations were carried out until the regime was established, and the sum of the flow rate taken into the channel and the flow rate at the outlet from the area would become equal to the water flow rate at the inlet. In this work, the possibility of constructing a batch-type sedimentation tank with hydraulic flushing was studied. At the same time, it was assumed that all sediments entering with the river flow should be retained in the sedimentation tank, except for a fraction of $0.0015 \mathrm{~mm}$ and finer. As an additional condition, it was taken into account that the distance from the end of the sedimentation tank to the front chamber of the first pumping station should be at least 1.0 $\mathrm{km}$.

The Amu Darya river, adjacent to the channel during the flood and during the low-water period, does not exceed $0.8 \mathrm{~m}$. So, for example, at a water flow rate of $6,800 \mathrm{~m} 3 / \mathrm{s}$, the water level in the river. The Amu Darya channel at the entrance is $245.89 \mathrm{~m}$, and at a distance of two kilometers is $245.45 \mathrm{~m}$. At the same time, the difference in water level marks in the channel and the river at a comparable distance does not exceed $0.15 \mathrm{~m}$.

In the case of a sedimentation tank with hydraulic flushing, the required difference between the beginning of the washing gallery and the water level in the river to obtain the water velocity capable of transporting sediments deposited in the sedimentation tank chamber must be at least 


$$
D_{h}=\Sigma \xi \frac{V_{\text {मp }}^{2}}{2 g}
$$

where: $\Sigma \xi$ is the sum of the coefficients of hydraulic losses in the gallery, $V_{n p}$ - water flow rate in the washing gallery, $\mathrm{g}$ is the acceleration of gravity.

To create a sufficient wash flow rate, at least not less than

$$
V_{\text {flushing }} \geq \omega \frac{h_{\text {flushing }}}{d} P^{1.85}=2.6 \mathrm{~m} / \mathrm{s}
$$

where: $d$ is the particles diameter, the sediment to be flushed less than which the sediment contains $75 \%, \omega$ is the hydraulic size of such particles, $h_{\text {flushing }}$ is the flush depth, $P$ is the percentage by weight of sediment in the washing flow, the required differential must be at least $1.85 \mathrm{~m}$.

In the sedimentation tank for periodic or continuous flushing, a regulating structure equipped with gates should be located at the head of the channel. The chambers of the sedimentation tanks should be concreted to ensure the appropriate hydraulic regime. At the end of the sedimentation tank should also be built a regulating structure equipped with washing galleries. At the same time, it is necessary to consider that the creation of appropriate structures will lead to a decrease in the water level along the entire length of the channel, which will negatively affect the operation of the pumping units.

It is impossible to set up a sedimentation tank with hydraulic flushing considering the absence of the necessary difference in water levels under any hydrological conditions (flood, low water). Thus, in the existing hydrological, hydraulic, and topographic conditions, a technically acceptable solution is a batch-type sedimentation tank device.

The main tasks in determining the size of the sedimentation tank are to determine its geometric dimensions and silting time since these parameters have the greatest impact on its operational characteristics and ultimately both the capital costs of its construction and the operating costs of its maintenance.

The most unfavorable conditions were taken as the initial data for calculating the sedimentation tank in order to ensure the operation of the hydraulic structures of the cascade, including pumping stations, even under such conditions, in particular, this concerns the water flow rate and the weighted average turbidity of the flow, i.e., all sediments entering with the river flow, except a fraction of $0.0015 \mathrm{~mm}$ and finer, should be retained in the sedimentation tank. Thus, the following parameters were taken into account in the calculations:

- The flow rate entering the sedimentation tank $Q=120 \mathrm{~m}^{3} / \mathrm{s}$.

- Sedimentation tank depth $H=7.42 \mathrm{~m}$.

- The average speed of water flow in the sedimentation tank $V_{a v}=0,25 \mathrm{~m} / \mathrm{s}$.

- Weighted average turbidity at the inlet to the sedimentation tank $\rho_{0}=3.6 \mathrm{~kg} / \mathrm{m} 3$.

- Diameter of the smallest fraction to be retained in the sedimentation $\operatorname{tank} D=$ $0.05 \mathrm{~mm}$.

- Hydraulic size of the finest fraction, which must be retained in the sedimentation tank

$\omega=0.00178 \mathrm{~m} / \mathrm{s}$.

- Average weighted hydraulic sediment size $w_{0}=0.00706 \mathrm{~m} / \mathrm{s}$.

- The granulometric composition of sediments entering the channel was adopted according to the recommendations [12].

Based on the information on the granulometric composition of the sediments entering the channel with river water and the hydraulic characteristics of the channel, it is possible to 
preliminarily determine the length of the sedimentation tank by setting the water velocity in it.

The width of the sedimentation tank was taken equal to the design width of the channel and the water flow velocity in it $V_{a v}=0.25 \mathrm{~m} / \mathrm{s}$, taking into account the recommendations [5]. For a rectangular section of the sedimentation tank and at a water flow rate of $0.25 \mathrm{~m} / \mathrm{s}$, the length of the sedimentation tank, which ensures the retention of sediments of the finest fraction $(0.05 \mathrm{~mm}$ in diameter $)$, for which there is information on its content in accordance with [12], is:

$$
L=H V / \omega=7.42 \cdot 0.25 / 0.00178=1042 \mathrm{~m}
$$

where $L$ is the sedimentation tank length, $V$ is the average water flow rate in the sedimentation tank.

One of the most important characteristics from the point of view of operation is the sedimentation time of the sedimentation tank. It is possible to determine the likely duration of the sedimentation process in the sedimentation tank, considering the weighted average turbidity of the water entering the sedimentation tank and the need for continuous water supply to pumping station No 1 .

The calculation of the sedimentation time of the sedimentation tank is made as follows. Calculating $\boldsymbol{\omega} / \boldsymbol{V}$ and $\boldsymbol{H} / \boldsymbol{L}$ according to the recommendations, we find the probability of sedimentation of the calculated fraction $\boldsymbol{P}=\mathbf{9 8} \%$, i.e., at least $98 \%$ of sediments with a diameter of $0.05 \mathrm{~mm}$ and larger will be retained in the sedimentation tank.

The lack of detailed information on the distribution of sediment inflow into the channel does not make it possible to make a more accurate forecast of the siltation time of the sedimentation tank. Nevertheless, provided that the water intake operates following the schedule shown in Figure 1, and constant weighted average turbidity, the volume of siltation per year will be $253298 \mathrm{~m}^{3}$. The sedimentation tank, under such operating conditions, can be completely silted in 19 months.

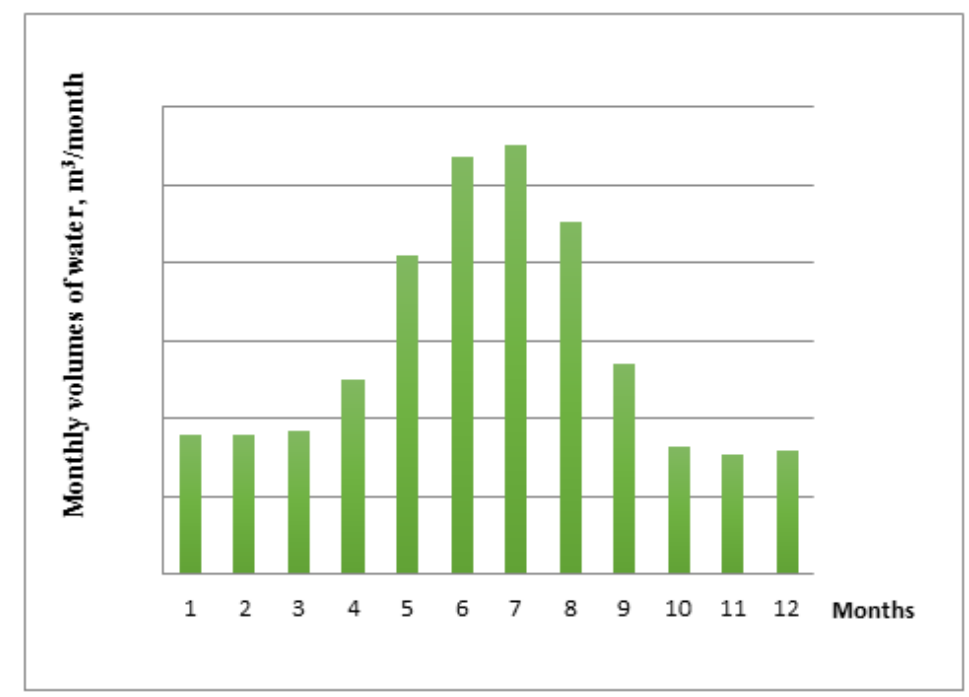

Fig. 1. Average monthly volumes of water [12] passed through the idle part of the channel in $2001-$ 2017. ( $\mathrm{m}^{3} /$ month) 
The siltation time of the sedimentation tank can be reduced by $15 \ldots 20 \%$ and amount to about 15 months, considering the unevenness of the velocity distribution diagram in the horizontal plane and the trapezoidal cross-section of the clarifier. Nevertheless, the arrangement of two parallel chambers of sedimentation tanks allows for a stable supply of clarified water for a sufficiently long time and, at the same time, for cleaning the silted chamber.

\section{Conclusions}

The performed analysis of the results of field and numerical studies led to the following conclusion:

1. The performed hydraulic calculations made it possible to show that there is no possibility of constructing a continuous hydraulic flushing sedimentation tank or a periodic flushing sedimentation tank with hydraulic flushing under existing conditions. It was shown that it is possible to construct a periodically operated sedimentation tank with mechanical cleaning on the inlet channel, which makes it possible to ensure continuous, year-round operation of the cascade and fulfill the condition of preventing sediment from entering the transit zone, which harms the operational characteristics of channels and pumping equipment

2. According to the results of numerical studies, the width of the sedimentation tank was taken equal to the design width of the channel and the speed of water flow in it $V_{a v}=$ $0.25 \mathrm{~m} / \mathrm{s}$. For a rectangular section of the sedimentation tank and at a water flow rate of $0.25 \mathrm{~m} / \mathrm{s}$, the length of the sedimentation tank, which ensures the retention of sediments of the finest fraction $(0.05 \mathrm{~mm}$ in diameter), for which there is information on its content in accordance with [12], is:

$$
L=H V / \omega=7.42 \cdot 0.25 / 0.00178=1042 \mathrm{~m} ;
$$

3. Provided that the water intake works according to the the schedule shown in fig. 1, and constant weighted average turbidity, the volume of siltation for the year will be 253298 $\mathrm{m} 3$, and the sedimentation tank, under such operating conditions, can be completely silted up in 19 months. The siltation time of the sedimentation tank can be reduced by $15 \ldots 20 \%$ and amount to about 15 months, considering the unevenness of the velocity distribution diagram in the horizontal plane and the trapezoidal cross-section of the clarifier. Nevertheless, the arrangement of two parallel chambers of sedimentation tanks allows for a stable supply of clarified water for a sufficiently long time and, at the same time, for cleaning the silted chamber.

\section{References}

1. Bazarov D., Shodiev B., Norkulov B., Kurbanova U., Ashirov B. Aspects of the extension of forty exploitation of bulk reservoirs for irrigation and hydropower purposes, E3S Web of Conferences, 97, (2019), DOI:10.1051/e3sconf/20199705008.

2. Bazarov D., Mavlyanova D. Numerical studies of long-wave processes in the reaches of hydrosystems and reservoirs. Magazine of Civil Engineering, (2019). 87(3), pp. 123-135. DOI:10.18720/MCE.87.10.

3. Bazarov D., Uralov B., Matyakubov B., Vokhidov O. The effects of morphometric elements of the channel on hydraulic resistance of machine channels of pumping stations. Mater. Sci. Eng. 869, (2020), DOI:10.1088/1757-899X/869/7/072015 
4. Krutov A., Choriev R., Norkulov B., Mavlyanova D., and Shomurodov A. Mathematical modelling of bottom deformations in the kinematic wave approximation. IOP Conf. Ser. Mater. Sci. Eng. 1030, (2021)

5. Bazarov D., Markova I., Raimova I., Sultanov S. Water flow motion in the vehicle of main channels. IOP Conference Series: Materials Science and Engineering, 883, (2020), DOI:10.1088/1757-899x/883/1/012001

6. Bazarov D., Shaazizov F., Erjigitov S. Transfer of Amudarya flowing part to increase the supportability of the Uzbekistan southern regions, IOP Conference Series: Materials Science and Engineering, 883, (2020), DOI:10.1088/1757899x/883/1/012068.

7. Rakhmatov N., Nazaraliev D., Artykbekova F., Uljaev F., Sapaeva M., Jumanov O. Improving the efficiency of lead exploitation pumping station channels, IOP Conf. Ser. Mater. Sci. Eng. 883, (2020), https://doi.org/10.1088/1757-899x/883/1/012009

8. Krutov A., Norkulov B., Uljaev F., and Jamalov F. Results of a numerical study of currents in the vicinity of a damless water intake, IOP Conf. Ser. Mater. Sci. Eng. 1030, (2021)

9. Krutov A., Norkulov B., Mavlyanova D. Simulation of spreading of non-conservative passive substances in water bodies, IOP Conf. Ser. Mater. Sci. Eng. 883(1), (2020)

10. Krutov A., Norkulov B., Nurmatov P., Mirzaev M. Applicability of zero-dimensional equations to forecast nonconservative components concentration in water bodies. IOP Conf. Ser. Mater. Sci. Eng. 883(1), (2020)

11. Krutov A., Norkulov B., Artikbekova F., Nurmatov P. Optimal location of an intake at a reservoir prone to salt diffusion. IOP Conf. Ser. Mater. Sci. Eng. 869(7), (2020)

12. Shokirov B., Norkulov B., Nishanbaev Kh., Khurazbaev M., Nazarov B. Computer simulation of channel processes, E3S Web of Conferences, 97, (2019)

13. Shomayramov M., Norkulov B., Rakhmanov J., Tadjiyeva D., Suyunov J. Experimental researches of hydraulic vacuum breakdown devices of siphon outlets of pumping stations. E3S Web of Conferences, 97, 05009, (2019)

14. Arefiev N., Mikhalev M., Zotov D., Zotov K., Vatin N., Nikonova O., Skvortsova O., Pavlov S., Chashina T., Kuchurina T., Terleev V., Badenko V., Volkova Y., Salikov V., Strelets K., Petrochenko M., Rechinsky A. Physical modeling of suspended sediment deposition in marine intakes of nuclear power plants. Procedia Engineering, 117(1), pp. 32-38, (2015), DOI:10.1016/j.proeng.2015.08.120

15. Dilshod B., Markova I., Sultanov S., Kattakulov F. Dynamics of the hydraulic and alluvial regime of the lower reaches of the Amudarya after the commissioning of the Takhiatash and Tuyamuyun hydrosystems, IOP Conference Series: Materials Science and Engineering, 1030, pp. 2021, DOI:10.1088/1757-899X/1030/1/012110.

16. Bazarov D., Vatin N., Bakhtiyor O., Oybek V. Hydrodynamic effects of the flow on the slab of the stand in the presence of cavitation. IOP Conference Series: Materials Science and Engineering. 2021. 1030. Pp. 012110. DOI:10.1088/1757899X/1030/1/012116.

17. Eshev, S., Latipov, S., Qurbonov, A., Sagdiyev, J., Berdiev, M., Mamatov, N. Noneroding speed of water flow of channels running in cohesive soils. IOP Conference Series: Materials Science and Engineering, 1030, (2021) DOI:10.1088/1757899x/1030/1/012131.

18. Eshev S., Rakhimov A., Gayimnazarov I., Isakov A., Shodiev B., Bobomurodov, F. Dynamically stable sections of large soil channels taking into account wind waves. IOP Conference Series: Materials Science and Engineering, 1030, (2021), DOI:10.1088/1757-899x/1030/1/012134 
19. Krutov A., Norkulov B., Uljaev F., Jamalov F. Results of a numerical study of currents in the vicinity of a damless water intake. IOP Conference Series: Materials Science and Engineering, 1030, (2021), DOI:10.1088/1757-899x/1030/1/012121

20. Uralov B., Rakhmatov N., Khidirov S., Safarov G. Hydraulic modes of damless water intake, (2021), DOI:10.1088/1757-899X/1030/1/012123

21. Anghesom A. Ghebrehiwot, Kozlov D.V. Spatial and Statistical Variability Analyses of Satellite-Based Climatic Data in Mereb-Gash Basin, Water Resources, 48(1), pp. 146-157, (2021)

22. Bednaruk S.E., Chukanov V.V., Klenov E.M., Kozlov D.V. Accounting for the Thermal State of the Sayano-Shushenskaya Dam to Determine the Safe Maximum Water Levels in the Reservoir in Developing Its Dispatch Schedules, Power Technology and Engineering, 54(4), pp. 451-455, (2020)

23. Khanov N.V., Martynov D.Y., Novichenko A.I., Lagutina N.V., Rodionova S.M. Outlook and Special Properties of Earth Anchors and Screw Piles in Burial of Modular Protection Dikes in Nonrocky Ground, Power Technology and Engineering, 52(4), pp. 405-412, (2018)

24. Kurbanov S.O., Khanov N.V. To calculation of the critical depths of the channels with polygonal profile (PP), Gidrotekhnicheskoe Stroitel'stvo, 3, pp. 42-44, (2004)

25. Kurbanov S.O., Khanov N.V. To hydraulic calculation of the most favorable sections of the power diversion channels (PDC) of a polygonal profile, Gidrotekhnicheskoe Stroitel'stvo, 7, pp. 40-43, (2003)

26. Khafizov A.R., Kamaletdinov F.F., Yakushkina A.B., Nedoseko I.V. Construction regulatory systems to protect the banks of the Ufa river in the area of Ufa water intake, Izvestiya KGASU. No1(51), pp.118-127, (2020)

27. Mukhametrakhimov R.Kh., Aliullova I.R. Improvement of the quality control system for expansion joints with rubber compensators during the repair of bridge constructions, Izvestiya KGASU. No3(53), pp.47-55, (2020)

28. Mukhametrakhimov R.Kh., Panchenko A.A. Features of the quality control system for the construction of outdoor water supply and sewerage networks, Izvestiya KGASU. No4(42), pp.360-367, (2017)

29. Kozlov D.V., Kuleshov S.L. Multidimensional Data Analysis in the Assessment of Ice-Jam Formation in River Basins, Water Resources, 46(2), pp. 152-159, (2019) 